\title{
O Caminho da Escola para os Estudantes com Deficiência: o Transporte Escolar Acessível no Plano Viver sem Limite ${ }^{1}$ \\ The Way to School for Students With Disabilities: Accessible SCHOol Bus in LIVING Without LIMITS PROGRAM
}

\author{
Andreia Couto RIBEIRO ${ }^{2}$ \\ Vanessa Teresinha Alves TENTES 3
}

\begin{abstract}
RESUMO: este estudo exploratório objetiva analisar a situação da política pública de transporte escolar urbano acessível, implantada para contribuir com o acesso dos estudantes com deficiência ou mobilidade reduzida, que estão fora da escola da Educação Básica. Nesse contexto, são analisados os objetivos, estratégias e financiamento do projeto do ônibus escolar acessível do Programa Caminho da Escola, no contexto do Plano Nacional dos Direitos da Pessoa com Deficiência - Viver sem Limite, tendo por referência a meta 4 e a estratégia 4.6 do novo Plano Nacional de Educação. Realizou-se uma pesquisa documental para abordar as condiçóes de acesso dos estudantes com deficiência à escola e apresentar o histórico da política educacional, identificando seus investimentos e sua abrangência.
\end{abstract}

PALAVRAS-CHAVE: Política Pública. Acessibilidade. Transporte Escolar.

\begin{abstract}
The objective of this exploratory study is to analyze the situation of public policies on accessible school buses, which were set to contribute to access of students with disabilities or reduced mobility, who are excluded from K-12 schools. In this context, the objectives, strategies and financing of the accessible school bus of "Way to School Program" are analyzed, in the context of the National Plan of Rights of Persons with Disabilities - Living without Limits, with reference to the goal 4 and 4.6 strategy of the new National Education Plan. We conducted document research to address the conditions students with disabilities have to access to school and present the history of educational policy, identifying its investments and its scope.
\end{abstract}

KEYWORDS: Public Policy. Accessibility. School Bus.

\section{INTRODUÇÁO}

A inclusão escolar é um movimento de profunda transformação da sociedade que vem ocorrendo nos últimos anos no âmbito dos direitos humanos, não somente em nosso País como no mundo todo, envolvendo mudanças de atitudes, com rompimento da discriminação e preconceito e o respeito às diferenças, o reconhecimento de barreiras de acesso, permanência e participação dos estudantes com deficiência nos ambientes escolares. Apesar das significativas mudanças, Tentes e Rocha (2014) destacam que o território da Educação Especial continua cercado por distintas insatisfaçōes e anseios, para fazer valer o direito universal à educação.

Segundo Slee (2013), é difícil entender a inclusão, pois se tornou um termo genérico, dividido por competição e contradiçôes, com debates ideológicos, para o enfrentamento entre os diferentes entendimentos de deficiência e incapacidade, correspondentemente à forma e aos

\footnotetext{
${ }^{1}$ http://dx.doi.org/10.1590/S1413-65382216000100003

${ }^{2}$ Mestranda em Educação pela Universidade Católica de Brasília (UCB), Técnica do Fundo Nacional de Desenvolvimento da Educação (FNDE/MEC), Brasília, Distrito Federal, Brasil. andreia.ribeiro@fnde.gov.br

${ }^{3}$ Doutora em Psicologia pela Universidade de Brasília (UnB), professora do Programa de Pós-Graduação em Educação da Universidade Católica de Brasília (UCB), Brasília, Distrito Federal, Brasil. psivan@terra.com.br
} 
objetivos da educação para estudantes com deficiência, como os discursos que posicionam as pessoas com deficiência como incapazes, doentes e objetos de piedade e caridade.

Desde 1988, o direito à educação para todos, sem nenhum tipo de discriminação, é garantido pela Constituição Federal (BRASIL, 1988). Baseado nessa premissa, os sistemas de ensino responsáveis pela escolarização de todos os estudantes, devem atender as demandas dos estudantes com deficiência, que encontram barreiras de acesso para participação no ensino regular. Dentre essas barreiras, destaca-se a questão da dificuldade da mobilidade e do transporte adequado para o trajeto do estudante deficiente, da sua casa até o ambiente escolar.

O Censo Demográfico do IBGE/2010 aponta que aproximadamente 23,9\% da população brasileira (cerca de 45 milhôes de pessoas) têm alguma deficiência. Partindo dessa demanda e o desafio de vencer o preconceito e discriminação, o acesso dos alunos com deficiência, nas salas de aula do ensino regular, tem crescido a cada ano. De acordo com os resultados do Censo Escolar/2012, a matrícula de alunos com deficiência em classes comuns, aumentou de 46,8\% em 2007, para 75,7\% em 2012 (BRASIL, 2014a).

$\mathrm{O}$ aumento da presença de estudantes com deficiência na escola tem permitido a reflexão sobre a acessibilidade em todos os sentidos, inclusive naqueles que se referem às adequaçôes de infraestrutura e de espaço, que ainda impedem a participação de qualquer pessoa na escola.

Apesar das previsões legais, para assegurar o acesso e a permanência das pessoas com deficiência nas instituiçóes regulares de ensino, previstas na Constituição Federal de 1988 (BRASIL, 1988), no Inciso III, Art. 4º da Lei de Diretrizes e Bases da Educação (LDB) (BRASIL, 1996) e no Inciso III, Art. 54 do Estatuto da Criança e do Adolescente (ECA) (BRASIL, 1990), essa presença somente pode ser viabilizada como atendimento de uma série de estruturas e serviços, dentre os quais se destaca o transporte escolar.

Além disto, a Meta 4, do novo Plano Nacional de Educação (PNE) (BRASIL, 2014b), afirma o direito de acesso de toda a população com deficiência, transtorno global de desenvolvimento e altas habilidades ou superdotação, bem como a Estratégia 4.6, a necessidade de manutenção e ampliação de programas suplementares de acessibilidade (BRASIL, 2014b).

O serviço de transporte até a escola é complexo tanto nas cidades como no campo, sendo mais crítico principalmente para alunos de baixo status socioeconômico, e podendo ser impeditivo para que crianças e jovens deficientes cheguem até as escolas, considerando a necessidade de veículos específicos, padronizados, com condições especiais para diminuir as barreiras físicas impostas pelos ambientes.

Com o intuito de promover a inclusão escolar, o Governo Federal realizou, no período de 2009 a 2010, uma Pesquisa Domiciliar para identificar barreiras que impedem o acesso e permanência na escola das crianças e adolescentes atendidas com o Benefício da Prestação Continuada $(\mathrm{BPC})^{4}$. Como resultado da pesquisa identificou-se que a falta de transporte acessí-

\footnotetext{
${ }^{4}$ O Benefício de Prestação continuada da Assistência Social - BPC foi instituído pela Constituição Federal de 1988 e regulamentado pela Lei Orgânica da Assistência Social - LOAS, Lei no 8.742, de 7/12/1993. Trata-se de um benefício individual, não vitalício e intransferível, que assegura a transferência mensal de um salário mínimo ao idoso, com 65 anos ou mais, e à pessoa com deficiência, de qualquer idade, com impedimentos de longo prazo, de natureza física, mental, intelectual ou sensorial, que comprovem uma renda mensal familiar per capita inferior a $1 \frac{1}{4}$ (um quarto) do salário mínimo vigente.
} 
vel foi indicada como um dos principais motivos para o não acesso das pessoas com deficiência à escola (BRASIL, 2011a).

Considerando a conjuntura apresentada pela pesquisa, a Uniáo lançou pelo Decreto no 7.612/2011, de 17 de novembro de 2011, o Plano Nacional dos Direitos da Pessoa com Deficiência - Viver sem Limite, com o objetivo de implementar novas iniciativas e intensificar açôes, que já estavam sendo desenvolvidas em benefício das pessoas com deficiência. $\mathrm{O}$ Viver sem Limite conta com a parceria entre os entes municipais, estaduais e do Distrito Federal e a equipe de 15 Ministérios ${ }^{5}$ e do Conselho Nacional dos Direitos da Pessoa com Deficiência (CONADE) (BRASIL, 2011b).

Seguindo o escopo do plano e, a demanda da sociedade e para garantir as condiçóes de acesso e permanência na escola e promover a inclusão escolar, o Governo Federal iniciou, em 2012, açóes para viabilizar a aquisição e distribuição de veículos para transporte escolar urbano acessível, a ser disponibilizado ao município com maior número de beneficiários do BPC, que estão fora da escola.

Nesse contexto, a ação de apoio a transporte escolar acessível para a área urbana foi incluída no Programa Caminho da Escola, no Plano Viver Sem Limite e nos principais instrumentos de planejamento orçamentário brasileiro, na Lei do Plano Plurianual (PPA) e na Lei Orçamentária Anual (LOA) (BRASIL, 1988).

As questôes que envolvem o atendimento aos beneficiários e a definição entre investimento e implantação da ação pública para o transporte urbano do estudante com deficiência é o objeto desse artigo e pretende abordar, por meio de um estudo exploratório e documental, a forma de execução, a definição dos beneficiários e a evolução dos recursos financeiros planejados e executados, considerando a implantação da ação.

\section{BREVE CONTEXTUALIZAÇÁO DO TRANSPORTE ESCOLAR ACESSÍVEL}

O transporte escolar urbano acessível é um projeto previsto no âmbito das metas e estratégias do PNE - 2014 a 2023, e das diretrizes da Política Nacional de Educação Especial ${ }^{6}$, e concretizado no Plano Viver Sem Limite e no Programa Caminho da Escola lançados pelo Governo Federal. A ação se apresenta como uma oportunidade para iniciar ou ampliar o acesso, a participação e a aprendizagem das pessoas com deficiência ou mobilidade reduzida nas classes comuns das escolas públicas da rede de ensino municipal, estadual e do Distrito Federal, contribuindo para a acessibilidade e a inclusão educacional.

${ }^{5}$ O Decreto no 7.612, de 17/11/2011 (BRASIL, 2011b), que instituiu o Plano Viver Sem Limite, estabeleceu a criação de Grupo Interministerial de Articulação e Monitoramento do Plano, com competência de promover a articulação dos órgãos e entidades envolvidos na implementação do Plano, com vistas a assegurar a execução, monitoramento e avaliaçáo das suas políticas, programas e açôes. O Grupo é composto por representantes dos seguintes órgãos: I - Secretaria de Direitos Humanos da Presidência da República: II - Casa Civil da Presidência da República;III - Secretaria Geral da Presidência da República;IV - Ministério do Planejamento, Orçamento e Gestáo;V - Ministério da Fazenda; VI - Ministério do Desenvolvimento Social e Combate à Fome; VII - Ministério da Saúde; VIII - Ministério da Educação; IX - Ministério da Ciência, Tecnologia e Inovação; X - Ministério da Previdência Social; XI - Ministério das Cidades; XII - Ministério do Esporte; XIII - Ministério do Trabalho e Emprego; XIV - Ministério das Comunicaçóes, e XV - Ministério da Cultura.

${ }^{6}$ Documento elaborado pelo Grupo de Trabalho nomeado pela Portaria Ministerial no 555, de 5 de junho de 2007, prorrogada pela Portaria no 948, de 09 de outubro de 2007. 
O PNE, um dos mais significativos instrumentos de planejamento da política educacional do País, com duração de 10 anos e vigência no decênio 2014-2023, foi aprovado pela Lei no 13.005 , de 25 de junho de 2014, trazendo significantes indicaçóes para a ação de transporte escolar para a Educação Básica. Dentre as metas do PNE, destaca-se a Meta 4, que traz em seu conceito, a previsão de universalizar o acesso à Educação Básica e ao atendimento educacional especializado, para a população de quatro a 17 anos com deficiência, transtornos globais do desenvolvimento e altas habilidades ou superdotaçáo, preferencialmente na rede regular de ensino, no intuito de garantir um sistema educacional inclusivo (BRASIL, 2014b).

Para o cumprimento dessa meta, o transporte escolar aparece na Estratégia 4.6, indicando a necessidade de oferta de transporte escolar adaptado, dentre as açóes de apoio aos alunos com necessidades educacionais especiais. A Estratégia 4.6 traz em seu conceito a seguinte indicação:

[...] Manter e ampliar programas suplementares que promovam a acessibilidade nas instituiçôes públicas, para garantir o acesso e a permanência dos (as) alunos (as) com deficiência, por meio da adequaçáo arquitetônica, da oferta de transporte acessível e da disponibilização de material didático próprio e de recursos de tecnologia assistiva, assegurando, ainda, no contexto escolar, em todas as etapas, níveis e modalidades de ensino, a identificação dos (as) alunos (as) com altas habilidades ou superdotaçấo (BRASIL, 2014b).

Também nesse contexto, na Política Nacional de Educação Especial (BRASIL, 2007a), o transporte escolar aparece como diretriz para assegurar a acessibilidade, cuja mensagem traz expressamente:

[...] A acessibilidade deve ser assegurada mediante a eliminação de barreiras arquitetônicas, urbanísticas, na edificação - incluindo instalaçóes, equipamentos e mobiliários - e nos transportes escolares, bem como as barreiras nas comunicaçōes e informaçóes (BRASIL, 2007a).

No Plano Viver Sem Limite, a ação aparece nas metas para o período 2011 a 2014 , no eixo de acesso à educação, com a previsão de distribuição de 2.609 ônibus escolares acessíveis, para beneficiar cerca de 60.000 estudantes com deficiência. $\mathrm{O}$ atendimento é prioritário para os municípios com maior número de beneficiários do BPC, em idade escolar obrigatória e que estão fora da escola. O objetivo é transportar os estudantes para as aulas e para o atendimento educacional especializado (BRASIL, 2013).

Para sua operacionalização, o projeto do ônibus urbano escolar acessível foi incluído no Programa Caminho da Escola, criado pela Resolução no 3, de 28 de março de 2007 (BRASIL, 2007b), com o objetivo de padronizar os veículos de transporte escolar, com vistas a melhoria da qualidade e dos elementos de segurança, redução dos preços dos veículos e o aumento da transparência nas aquisiçóes governamentais.

O Caminho da Escola faz parte da política pública de investimento ao transporte escolar implantada desde 1993, pelo Governo Federal, no intuito de contribuir para a condução dos alunos no trajeto residência e escola e atuar no problema dos estudantes que residem à grande distância das unidades escolares, pretendendo garantir a frequência às aulas e reduzir os índices de evasão escolar. 
No contexto histórico dessa Política no âmbito federal, além do Caminho da Escola, destaca-se a assistência técnica e financeira da União aos municípios e estados, mediante o atendimento com programas suplementares de transporte para o estudante da Educaçáo Básica, garantidos pela Constituição Federal de 1988, no inciso VII do art. $208^{7}$ (BRASIL, 1988) e,pela Lei de Diretrizes e Bases da Educação Nacional (LDB), no 9.394 de 20 de dezembro de 1996, no inciso VIII do art.4o (BRASIL, 1996), iniciado em 1994 pelo Programa Nacional de Transporte Escolar (PNTE) e alterado em 2004, passando a denominar de Programa Nacional de Apoio ao Transporte Escolar (PNATE).

Os Programas atualmente gerenciados pelo Fundo Nacional de Desenvolvimento da Educação $(\mathrm{FNDE})^{8}$, órgão vinculado ao Ministério da Educação (MEC), em colaboração com estados e municípios, envolvem questóes de autonomia dos sistemas federativos, descentralização de políticas públicas, distribuição de recursos financeiros,a forma de atendimento ao público alvo e a auditoria e controle da gestão, considerando a necessidade de maior atenção aos que tem maior vulnerabilidade e apresentam maior dificuldade de locomoção.

O Caminho da Escola consiste na aquisição de veículos padronizados, com especificaçóes exclusivas, próprias para transporte de estudantes e adequados às condiçóes de trafegabilidade das vias de trânsito. Os critérios para participação e adesão dos entes federais, seguem as definiçóes pactuadas no Plano de Açóes Articuladas (PAR) (BRASIL, 2012).

O PAR é um instrumento de planejamento multidimensional e plurianual da política de educação, concebido de forma estratégica pelos sistemas educacionais de cada esfera de governo - municipal, estadual e do Distrito Federal, com apoio dos gestores e educadores de sua rede administrativa, com intuito de estruturar e gerenciar metas definidas e racionalizar o uso de recursos no âmbito educacional e, alcançar objetivos ligados diretamente ao desenvolvimento educacional do País (BRASIL, 2012c). A partir do diagnóstico da realidade local, estruturado pelo Plano, propóe-se a atuação e a priorização das açóes pelos órgãos educacionais, dentre as quais a viabilização de construção e de contratação do produto escolar almejado.

O processo de concepção do ônibus urbano escolar acessível, no âmbito do Caminho da Escola, considerou a criação de um veículo com a possibilidade de adaptação ou de adequação do mobiliário e das instalaçóes dependendo da quantidade de estudantes com deficiência ou restrição de mobilidade, a serem beneficiadas em cada rota. Os conceitos fundamentais de mobilidade e multifuncionalidade do veículo foi resultado da discussão técnica entre especialistas da educação especial e dos direitos humanos, do Instituto Nacional de Metrologia, Qualidade e Tecnologia (Inmetro), da área de compras governamentais da educação e de fabricantes e montadores de veículos.

Como consequência da articulação se chegou a um ônibus de porte pequeno, com possibilidade de transportar até 21 estudantes deficientes, construído com características específicas para uso em vias pavimentadas e dotado de elementos como a plataforma elevatória veicular,

\footnotetext{
${ }^{7}$ Alterado pela Emenda Constitucional no 59, de 2009 e pela Lei no $12.796 / 2013$, quando o atendimento foi estendido para toda a Educaçáo Básica (BRASIL, 2013).

${ }^{8}$ O Fundo Nacional de Desenvolvimento da Educação (FNDE) é uma autarquia federal criada pela Lei no 5.537 , de 21 de novembro de 1968, e alterada pelo Decreto Lei no 872, de 15 de setembro de 1969, é responsável pela execuçâo de políticas educacionais do Ministério da Educação (MEC).
} 
o box reservado para acomodação da cadeira de rodas com o seu acompanhante ou o cão guia, poltronas preferenciais, com cinto de segurança subabdominal, sistema de comunicação para informação aos estudantes com deficiência visual ou auditiva e comunicação visual interna e externa, com símbolos específicos e sinalização tátil, que o torna acessível aos estudantes deficientes.

O veículo é adquirido, por meio de pregão eletrônico para registro de preços nacional, que consiste em uma compra pública única e compartilhada baseada na demanda planejada e indicada como necessária pelos órgãos de educação do País, por meio do PAR. É um modelo que traz um novo conceito de assistência técnica da União aos estados e municípios, disponibilizando um produto padronizado, licitado para que os entes governamentais possam contratar e receber nas localidades planejadas. Os veículos disponibilizados apresentam quatro configuraçóes intercambiáveis, demonstradas nas possibilidades do Quadro 1, que permitem a substituição de mobiliários e espaços, para atender as diversas demandas de acomodação.

\begin{tabular}{|l|l|l|}
\hline \multicolumn{2}{|l|}{ Configuraçáo do ônibus } & Capacidade aproximada \\
\hline 01 & $\begin{array}{l}\text { uma área reservada (box) para cadeirade } \\
\text { rodas }\end{array}$ & $\begin{array}{l}\text { Até 20 estudantes sentados e um estudante com cadei- } \\
\text { ra de rodas }\end{array}$ \\
\hline 02 & $\begin{array}{l}\text { duas áreas reservadas (box) para cadeira } \\
\text { de rodas }\end{array}$ & $\begin{array}{l}\text { Até 13 estudantes sentados e dois estudantes com } \\
\text { cadeira de rodas }\end{array}$ \\
\hline 03 & $\begin{array}{l}\text { três áreas reservadas (box) para cadeira de } \\
\text { rodas }\end{array}$ & $\begin{array}{l}\text { Até 11 estudantes sentados e três estudantes com } \\
\text { cadeira de rodas }\end{array}$ \\
\hline 04 & $\begin{array}{l}\text { quatro áreas reservadas (box) para cadeira } \\
\text { de rodas }\end{array}$ & $\begin{array}{l}\text { Até quatro estudantes sentados e quatro estudantes } \\
\text { com cadeira de rodas }\end{array}$ \\
\hline
\end{tabular}

Quadro 1 - Configuraçóes do ônibus urbano escolar acessível.

Fonte: Portal de Compras do FNDE/MEC.

A representação do projeto gráfico das quatro opções de configurações de ônibus acessível, disponibilizadas aos estados e municípios, é visualizada na Figura 1.

Opção 1: Veículo com uma área reservada (box) para
cadeira de rodas $\begin{aligned} & \text { Opção 2: Veículo com duas áreas reservadas (boxes) para } \\ & \text { cadeira de rodas }\end{aligned}$

Figura 1 - Configuraçóes do ônibus urbano escolar acessível

Fonte: Portal de Compras do FNDE/MEC. 


\section{O ATENDIMENTO E O FINANCIAMENTO DO TRANSPORTE ESCOLAR ACESSÍVEL}

O financiamento de recursos e serviços aos sistemas de ensino dos estados, municípios e do Distrito Federal, para a eliminação de barreiras no processo de escolarização, tais como o transporte escolar, é uma das estratégias para implantação da política de educação inclusiva pelo MEC. A estrutura e a organização desse financiamento, considerando a gestão, a execução e o controle das açóes, seguem os parâmetros e critérios do orçamento público, estabelecidos pela Lei do Plano Plurianual (PPA), a Lei de Diretrizes Orçamentárias (LDO) e a Lei Orçamentária Anual (LOA), os três instrumentos constitucionais de planejamento orçamentário brasileiro (BRASIL, 1988).

Farah (2012) salienta que o orçamento público é uma ferramenta de gestão, que define objetivos, programas e projetos, prioriza açóes e define metas, buscando respostas concretas aos problemas e demandas da sociedade. Dessa forma, o transporte escolar acessível foi incluído no PPA para o Período 2012/2015, intitulado Plano Mais Brasil (BRASIL, 2012b), com a meta de elevar a taxa de inclusão escolar das pessoas de 4 a 17 anos com deficiência, transtornos globais do desenvolvimento e altas habilidades ou superdotação na rede regular de ensino e pela Iniciativa $n^{\circ} 02 \mathrm{C} 0$, descrita a seguir:

[...] Prestação de assistência financeira, técnica e material as escolas, aos profissionais da educação e aos estudantes das redes públicas da educação básica, incluindo programas de transporte, alimentação (inclusive de professores e profissionais de educaçáo básica), assistência à saúde, manutenção escolar, ampliação do tempo e espaços educativos e reforço da autogestão, material didático-escolar, paradidático, periódicos e obras de referencia, considerando, entre outras especificidades, o atendimento educacional especializado, a acessibilidade, a sustentabilidade socioambiental, as populações do campo, afrodescendentes, indígenas e a educação de jovens e adultos (BRASIL, 2012b).

A partir dessa previsão, foram alocados créditos orçamentários do Governo Federal, na ordem de mais de trezentos milhões, para aquisição de 2.474 veículos, a serem distribuídos em 1.479 municípios, discriminados na Tabela 1. Os dados também apresentam a distribuição do atendimento por tipo de participação dos entes federados, por outras fontes de recursos, quando da adesão ao pregão eletrônico do FNDE.

Tabela 1 - Histórico de atendimento do caminho da escola - Transporte Escolar Acessível.*

\begin{tabular}{ll|l|l}
\hline \multicolumn{4}{c}{ Ônibus Urbano Acessível } \\
Tipo de recursos & Municípios & Veículos & Valor $(\mathrm{R} \$)$ \\
\hline $\begin{array}{l}\text { Recurso FNDE } \\
\text { Recurso Próprio }\end{array}$ & 1.479 & 2.474 & $345.342 .000,00$ \\
Recurso BNDES & 121 & 1.213 & $163.752 .000,00$ \\
\hline Total & 1.601 & 9 & $1.188 .000,00$ \\
\hline
\end{tabular}

* Execução apurada com base nas adesões ao registro de preços, exceto ônibus com recurso FNDE, apurada por meio de empenhos realizados.

Fonte: Painel SIMEC (2014). 
Cabe esclarecer que a forma de participação dos estados e municípios neste processo de aquisição de ônibus por meio do Programa Caminho da Escola ocorre de três maneiras: a) com recursos próprios advindos do Fundo de Manutenção e Desenvolvimento da Educação Básica e de Valorização dos Profissionais da Educação (Fundeb), do Salário Educação ${ }^{9}$ e, das demais fontes estaduais e municipais de recursos dos 25\% de impostos e contribuiçóes vinculados a educação (AMARAL, 2012); b) por transferência de recursos do FNDE, direta ao município ou estado que preenche e tem a ação prevista no Plano de Açóes Articuladas (PAR) aprovada pelo $\mathrm{MEC}$ e, c) por meio de financiamento do Banco Nacional de Desenvolvimento Econômico e Social (BNDES).

No âmbito do atendimento específico para os participantes do Plano Viver Sem Limite, o Gráfico 1 apresenta que do total de veículos distribuídos dos anos de 2012 a 2014, 2.305 foram adquiridos para os municípios amparados pelo Plano, o que equivale ao atendimento de $88 \%$ da meta prevista de 2.609 para o período, sendo o valor total utilizado na ordem de 314 milhóes de reais. Ressalta-se que esse valor náo equivale a 4\%, do montante do custeio previsto em 7,6 bilhóes de reais, para todas as açóes do Plano até 2014.

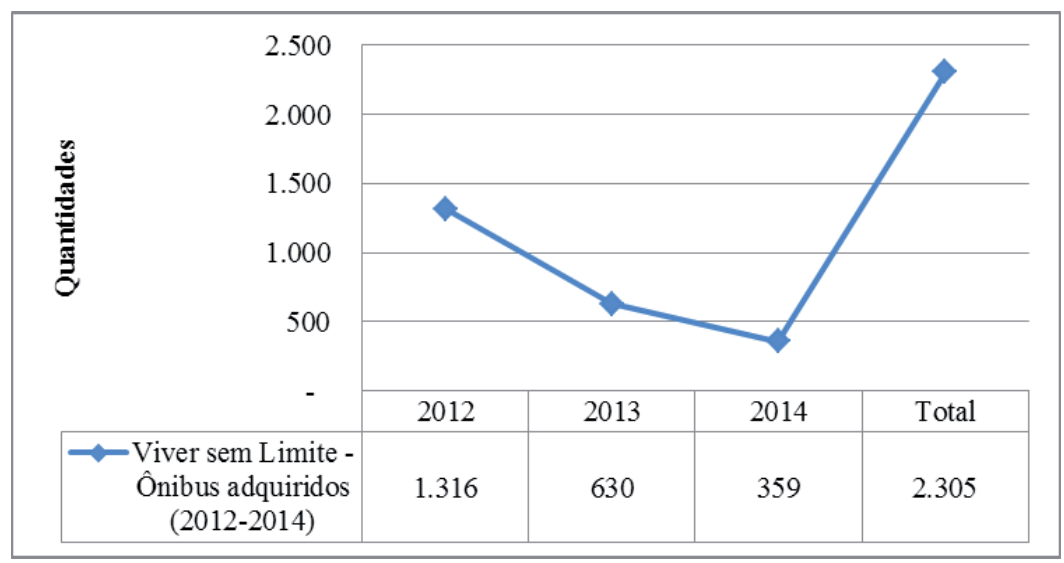

Gráfico 1 - Viver sem Limite - ônibus adquiridos 2012 - 2014.

Fonte: Painel SIMEC (2014).

Dentre os motivos pelo qual a situação da meta prevista, não tenha sido alcançada no prazo estipulado pelo Plano, pode ser explicado pelo fato do Caminho da Escola não ser regido por transferência automática de recursos. No programa, os recursos federais repassados pelo FNDE, para os municípios beneficiados, são realizados por transferência voluntária, ficando dependente de assinatura de convênio ou termo de compromisso. Os programas que dependem de convênios geralmente apresentam execução financeira mais baixa, isto ocorre, em face de limitaçóes.

Esses limites consistem em escolha de um rol de projetos prioritários de diversas áreas educacionais, possibilidade de corte orçamentário e financeiro, possibilidade de mudanças nas formas de atendimento dependendo da conjuntura econômica ou a prioridade do país, além

9Salário Educação: Contribuição de 2,5\% sobre a remuneração paga aos segurados empregados. 
de propiciar a intervenção político-partidária, por meio de pleitos efetuados por parlamentares, altos burocratas e dirigentes locais e regionais (PARENTE, 2001).

Baseando-se no resultado da Pesquisa Domiciliar para identificação das barreiras que impedem o acesso e permanência na escola dos beneficiários do BPC, realizada no período de 2009 a 2010, constata-se pelos dados apresentados no Gráfico 2, que os ônibus foram distribuídos em todas as regióes brasileiras. Entretanto o atendimento é diferenciado do previsto na pesquisa, sendo mais da metade, $51 \%$ ocorrendo somente na região Nordeste e as demais regióes com 49\% do benefício (BRASIL, 2013).

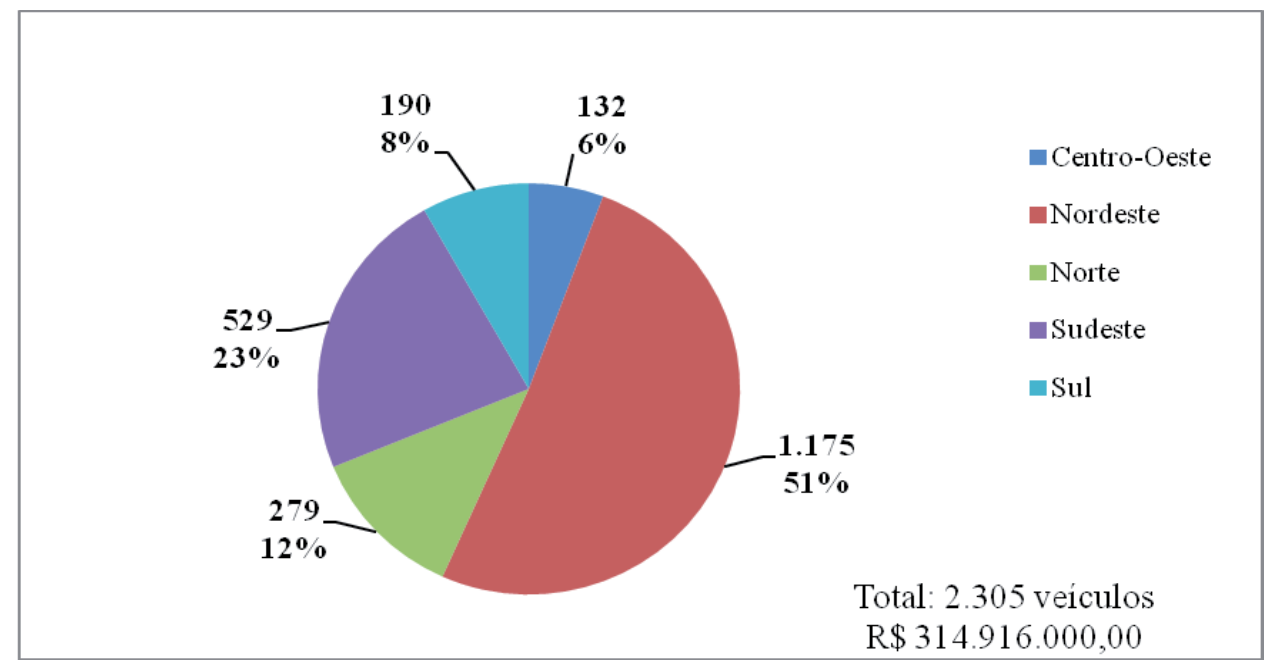

Gráfico 2 - Viver sem Limite - ônibus adquirido por região.

Fonte: Portal de SIMEC/Painel de indicadores (2014).

Esse resultado no atendimento se apresenta diferente dos interesses iniciais demonstrados no âmbito regional pela pesquisa, quando os participantes indicaram que dentre os principais motivos para o não acesso das pessoas com deficiência à escola, seria a falta de transporte acessível, computou-se que 35\% eram do Nordeste, 33\% do Centro-Oeste, 32\% do Norte, $28 \%$ do Sudeste e $23 \%$ do Sul e também, do planejamento idealizado para distribuição dos veículos, conforme Tabela 2 (BRASIL, 2011b).

Tabela 2 - Planejamento de Atendimento do Caminho da Escola - Transporte escolar acessível.

\begin{tabular}{|l|c|c|c|c|}
\hline Regiāo & \multicolumn{2}{|c|}{$\begin{array}{c}\text { No de beneficiários fora } \\
\text { da escola }\end{array}$} & $\begin{array}{c}\text { No de municípios } \\
\text { contemplados }\end{array}$ & $\begin{array}{c}\text { No de veículos plane- } \\
\text { jados }\end{array}$ \\
\hline Nordeste & 89.234 & $43 \%$ & 812 & 1.214 \\
\hline Centro Oeste & 11.511 & $6 \%$ & 63 & 127 \\
\hline Norte & 24.392 & $12 \%$ & 179 & 319 \\
\hline Sudeste & 61.438 & $30 \%$ & 339 & 740 \\
\hline Sul & 19.706 & $10 \%$ & 137 & 209 \\
\hline Total Brasil & 206.281 & $100 \%$ & 1.530 & 2.609 \\
\hline
\end{tabular}

Fonte: Nota técnica SEESP/MEC (2011b). 
Considerando os dados apresentados e, apesar de se demonstrar o crescimento no atendimento pretendido, verifica-se que ainda há necessidade de atendimento regional. Analisando as informaçóes de planejamento apresentadas na Tabela 2, comparando com os dados de aquisição de veículos (ver Gráfico 2), constata-se que a execução ficou em 88\%, faltando $12 \%$ de veículos para cumprimento da meta planejada para atendimento até 2014 . Regionalmente, destaca-se que o Sudeste, apresentou 71\% de execução com relação à previsão e o Norte chegou a 87\%, demonstrando que são regióes ainda carentes de atendimento.

Executar o programa seguindo o planejamento baseado nos resultados da pesquisa é uma importante ação para o sucesso da política no atendimento dos beneficiários. Analisando as informações de execução, constata-se que houve repasse de recursos do Governo Federal, para aquisição de 2.474 veículos em 1.479 municípios, desses 2.305 foram adquiridos para os municípios amparados pelo Plano, permitindo concluir que mais municípios que os apontados no planejamento inicial foram atendidos. Martins (2011) destaca que os objetivos do financiamento de obtenção da qualidade e equidade são prejudicados, quando os gastos são voltados para alunos das classes econômicas mais favorecidas, com o abandono das pessoas que realmente mais necessitam da ação.

A atualização da pesquisa para monitorar as pessoas com deficiência que ainda, se mantém fora da escola, devido à dificuldade de mobilidade, pode ser um instrumento para se constatar a efetividade da ação de transporte escolar e se demonstrar a necessidade de mudança de rumos e de beneficiários.

\section{Consideraçóes finais}

Podemos considerar que projetos educacionais como o de transporte escolar acessível implantado por meio de um planejamento e financiamento estruturados envoltos de uma política e planos públicos pode estabelecer um processo que constitui novos arranjos e modelos para a Educação Especial brasileira. O Viver sem Limite e o PAR, que envolvem a operacionalização do Programa Caminho da Escola para as pessoas com deficiência, parecem contribuir para implantação de uma gestão estratégica para apoiar a acessibilidade e a inclusão na escola.

Os discursos de qualidade da educação e a ideia de melhoria da gestão dos sistemas de ensino, de forma democrática e autônoma, elevam a importância de açóes como de transporte escolar, pelo reconhecimento dos gestores e estudiosos para garantir o desenvolvimento da educação do país. É evidente que o apoio aos sistemas educacionais não pode se restringir ao financiamento, é necessária a prestação de uma assistência técnica de qualidade, eficaz, eficiente e com participação coletiva, para contribuir não somente na execução dos recursos de forma adequada, mas também na organização da ação.

As informaçóes aqui levantadas nos conduzem ao entendimento de que açóes concretas e soluções viáveis, como o veículo escolar acessível, envolto de uma política e de plano de estado, podem se tornar elementos essenciais para a solução de problemas da realidade educacional brasileira. Entretanto, faz-se necessário ir além das análises aqui encontradas e, procurar construir entendimentos de como programas públicos são iniciados e não descontinuados, se tornando em políticas de Estado, mantendo-se em expansão, vinculados exclusivamente às necessidades das pessoas. 
Atualmente, o projeto do ônibus escolar acessível continua na agenda do Plano Viver sem Limite e mantido pelo Programa Caminho da Escola. Vem sendo reestruturado pelos especialistas no intuito de acrescentar, ao rol de opçóes, um novo modelo de veículo com piso baixo, que melhor atenda as necessidades das pessoas com deficiência e mobilidade reduzida.

Considerando os resultados apresentados, demonstrando o atendimento à demanda dos serviços de transporte escolar acessível, uns dos anseios da sociedade para propiciar o acesso à escola das crianças e jovens com deficiência ou mobilidade reduzida, podem concluir que o projeto contribui para diminuir as insatisfaçóes apontadas por Tentes e Rocha (2014), apoiando no enfrentamento das diferenças e questóes que envolvem o desenvolvimento da Educação Especial em nosso País.

\section{REFERÊNCIAS}

AMARAL, N. C. Para compreender o financiamento da educaçâo básica no Brasil. Brasília, DF: LíberLivro, 2012.

BRASIL. Constituição da República Federativa do Brasil de 1988. Brasília, DF: 1988. Disponível em: <http://www.planalto.gov.br/ccivil_03/Constituicao/Constituicao.htm>. Acesso em: 10 nov. 2014.

BRASIL. Lei no 8.069, de 13 de julho de 1990. Estatuto da Criança e do Adolescente. Brasília, DF: 1990. Disponível em: <http://www.planalto.gov.br/ccivil_03/leis/l8069.htm>. Acesso em 10 nov. 2014.

BRASIL. Lei no 9.394, de 20 de dezembro de 1996. Lei de Diretrizes e Base da Educação Nacional. Brasília, DF: 1996. Disponível em: <http://www.planalto.gov.br/ccivil_03/leis/19394.htm>. Acesso em 10 nov. 2014

BRASIL. Resolução/CD/FNDE no 3, de 28 de março de 2007. Cria o Programa Caminho da Escola. Brasília, DF: 2007b. Disponível em: <http://www.fnde.gov.br/programas/transporte-escolar/ transporte-escolar-legislacao>. Acesso em: 05 nov. 2014.

BRASIL. Resolução/CD/FNDE no 12, 17 de março de 2011. Estabelece os critérios e as formas de transferência de recursos financeiros do Programa Nacional de Apoio ao Transporte do Escolar (PNATE). 2011a. Disponível em: <http://www.fnde.gov.br/programas/transporte-escolar/transporteescolar-legislacao>Acesso em: 05 nov. 2014.

BRASIL. Casa Civil. Subchefia para Assuntos Jurídicos. Decreto no 7.612, de 17 de novembro de 2011. Institui o Plano Nacional dos Direitos da Pessoa com Deficiência - Plano Viver sem Limite. Brasília, DF: 2011b.

BRASIL. Nota técnica no 42 / 2011 / MEC / SECADI / DPEE, de 24 de outubro de 2011. 2011c. Disponível em: <http://portal.mec.gov.br/index.php?option=com_ content\&view=article\&id=18010\&Itemid=817>. Acesso em: 02 nov. 2014.

BRASIL. Lei No 12.695, de 25 de Julho de 2012. Dispóe sobre o apoio técnico ou financeiro da União no âmbito do Plano de Açóes Articuladas. 2012. Disponível em: <https://www.fnde.gov.br/fndelegis/ action/UrlPublicasAction.php?acao=abrirAtoPublico\&sgl_tipo=LEI\&num_ato=00012695\&seq_ ato=000\&vlr_ano=2012\&sgl_orgao=NI>. Acesso em: 10 nov. 2014 .

BRASIL. Secretaria de Direitos Humanos da Presidência da República (SDH/PR) / Secretaria Nacional de Promoção dos Direitos da Pessoa com Deficiência (SNPD). Viver sem Limite - Plano Nacional dos Direitos da Pessoa com Deficiência. Brasília, DF: SDH-PR/SNPD, 2013. 
BRASIL. Anuário Brasileiro da Educação Básica 2014. Todos pela Educação. São Paulo: Editora Moderna, 2014a.

BRASIL. Lei No 13.005, de 25 de Junho de 2014. Aprova o Plano Nacional de Educação - PNE e dá outras providências. 2014b. Disponível em http://www.planalto.gov.br/CCIVIL_03/_Ato20112014/2014/Lei/L13005.htm . Acesso em: 24 nov. 2014.

FARAH, M. F. Políticas públicas e desenvolvimento local. In: SILVA, C. (Org.). Orçamento público e gestäo governamental. Petrópolis: Vozes, 2012. p.39-67.

MARTINS, P. S. Fundeb, federalismo e regime de colaboração. Campinas: Autores Associados, 2011.

PARENTE, C. M. D. O processo decisório de implementação da Assistência Financeira do Fundo Nacional de Desenvolvimento da Educação (FNDE), via Planos de Trabalho (PTA), no Município de Vinhedo-SP (1997-1999). 2001. 222f. Dissertação (Mestrado em Educação) - Faculdade de Educação, Universidade Estadual de Campinas, Campinas, 2001.

SLEE, R. Um cortador de queijo com outro nome?Reduzindo a sociologia da inclusáo a pedaços. Porto Alegre: Penso, 2013.

TENTES, V.; ROCHA, A. Política públicas educacionais reconhecedoras da diferença: desafios da educação especial inclusiva no distrito federal. A educação em novas arenas: Políticas, pesquisas e perspectivas. Brasília, DF: Líber-Livro, 2014.

Recebido em : 27/07/2015

Reformulado em: 15/03/2016

Aprovado em: 16/03/2016 